Drew, J. H., and Acton, C. M. (1976). Radiological findings in newborn infants with urinary infection. Archives of Disease in Childhood, 51, 628-630.

Hodson, C. J., Maling, T. M. J., McManamon, P. J., and Lewis M. G. (1975). The pathogenesis of reflux nephropathy (chronic atrophic pyelonephritis). British Journal of Radiology, Suppl. 13.

McAlister, W. H., Cacciarelli, A., and Shackelford, G. D. (1974). Complications associated with cystography in children. Radiology, 111, 167-172.

McRae, C. U., Shannon, F. T., and Utley, W. L. F. (1974). Effect on renal growth of reimplantation of refluxing ureters. Lancet, 1, 1310-1312.

Rolleston, G. L., Maling, T. M. J., and Hodson, C. J. (1974). Intrarenal reflux and the scarred kidney. Archives of Disease in Childhood, 49, 531-539.

Rolleston, G. L., Shannon, F. T., and Utley, W. L. F. (1975). Follow-up of vesico-ureteric reflux in the newborn. Kidney International, 8, Suppl. 4, 59-64.

Smellie, J. M., and Normand I. C. S. (1975). Bacteriuria, reflux and renal scarring. Archives of Disease in Childhood, 50, 581-585.

Uldall, P., Frøkjaer, O., and Ibsen, K. K. (1976). Intrarenal reflux. Acta Paediatrica Scandinavica, 65, 711-716.

\section{Effect of ascorbic acid on urinary hydroxyproline in children receiving corticosteroids}

Sir,

Saphyakhajon et al. (1977), studying children receiving adrenal steroids for the treatment of juvenile rheumatoid arthritis (JRA), criticize our observations (Liakakos et al., 1974a), stating that they did not find an increase in the amount of urinary hydroxyproline (HOP) with the simultaneous administration of large doses of ascorbic acid. Our study material, however, did not include children with JRA. It consisted of 6 children with rheumatic fever and 2 with the nephrotic syndrome. The observed discrepancy between their results and ours may well be attributed to differences in the study material, as in JRA the amount of HOP in the urine is found to be diminished (Smith et al., 1968).

The same authors do not state the amount of steroids administered to their children. Our children received predisolone $2 \mathrm{mg} / \mathrm{kg}$ body weight per day. If, by any chance, the dose of corticosteroids administered was too small it could not cause a further reduction in the amount of already low values of HOP found in JRA. The authors also do not mention in their letter whether their children were receiving salicylates simultaneously with steroids on a standard therapeutic basis. As we have previously shown (Liakakos et al., 1974b), administration of therapeutic doses of aspirin to children causes a decreased urinary HOP which cannot be restored with administration of large doses of ascorbic acid.

Our recent observations in guinea pigs receiving corticosteroids have shown that prednisolone causes a narrowing in the epiphyseal plate of the tibia bones of these animals, whereas this effect is entirely inhibited with the simultaneous administration of ascorbic acid (unpublished data).
D. Liakakos, D. G. Ikkos, P. Vlachos, K. NTAlles, and C. Coulouris 2nd Department of the 'Aglaia Kyriakou' Children's Hospital, and Department of Endocrinology and Radioisotopes, 'Evangelismos' Hospital, Athens, Greece.

\section{References}

Liakakos, D., Ikkos, D. G., Vlachos, P., Ntalles, K., and Coulouris, C. (1974a). Effect of ascorbic acid on urinary hydroxyproline of children receiving corticosteroids. Archives of Disease in Childhood, 49, 400-403.

Liakakos, D., Vlachos, P., Doulas, N., and Ntalles, K. (1974b). Effect of ascorbic acid on urinary hydroxyproline of children receiving aspirin. Pediatriki, 37, 231-236.

Saphyakhajon, P., Grossman, B. J., and Quinn, J. (1977). Effect of ascorbic acid on urinary hydroxyproline of children receiving corticosteriods. Archives of Disease in Childhood, 52, 82.

Smith, M., Ansell, B. M., and Bywaters, E. G. L. (1968). Urinary hydroxyproline excretion in patients with juvenile rheumatoid arthritis with and without corticosteroid therapy. Journal of Pediatrics, 73, 875-881.

\section{Congenital abnormalities associated with extrahepatic portal hypertension}

Sir,

In the May issue of the Archives (1977, 52, 383), Odièvre and co-workers draw attention to the association of congenital abnormalities in children with extrahepatic portal hypertension of unknown cause. None of the children described by them nor those recorded in published reports had affected sibs.

We reviewed 8 patients with extrahepatic portal hypertension seen by us in the last 7 years. Of these, 1 had had omphalitis and 7 had extrahepatic portal hypertension of unknown cause. Of those 7 children, 3 had associated congenital abnormalities and 2 of these were in sibs. 1 patient had pyloric stenosis and congenital stricture of the sphincter of Oddi. The other 2 cases with extrahepatic portal hypertension were in brothers, 1 of whom had pulmonary stenosis and atrial septal defect, and the other pulmonary stenosis and pyloric stenosis. Atrial septal defect, pulmonary stenosis, and pyloric stenosis have all been described previously in association with extrahepatic portal hypertension.

This is the first report to our knowledge of the association of extrahepatic portal hypertension and congenital stricture of the sphincter of Oddi, and of the occurrence of extrahepatic portal hypertension and congenital abnormalities in sibs. These findings suggest that some cases of extrahepatic portal hypertension are not only congenital in origin, but might be genetically determined.

Philip Lanzkowsky Department of Pediatrics, Long Island Jewish-Hillside Medical Centre, New Hyde Park, New York 11040, USA. 